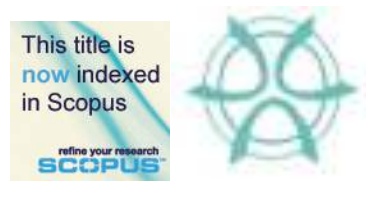

PLANNING MALAYSIA:

Journal of the Malaysian Institute of Planners

SPECIAL ISSUE IV (2016), Page 99 - 108

\title{
EVALUATING SIGNIFICANT FACTORS THAT INFLUENCE PUBLIC TRANSPORT USAGE IN KERMAN, IRAN
}

\author{
Azin Bahreini' ${ }^{1}$, Hamed Mirzaei ${ }^{2}$, Mehdi Moeinaddini ${ }^{3}$, Zohreh Asadi-Shekari", \\ Muhammad Zaly Shah ${ }^{5}$ \& Zahid Sultan 6 \\ 1,2,3,4,5,6 Faculty of Built Environment \\ UNIVERSITI TEKNOLOGI MALAYSIA
}

\begin{abstract}
Although public transport is recommended to develop a sustainable transport system, the percentage of daily trips by public transport in Iran specifically in medium sized cities such as Kerman is very low. Currently, efforts are being made to indicate significant factors that prevent public transport usage in developed countries but few studies have been conducted in developing countries. Only a few studies have considered public transport usage in Iranian megacities and medium sized cities such as Kerman require more attention. Therefore, this study tries to identify effective factors that influence public transport usage in urban areas in developing countries like Iran and in medium sized cities like Kerman. In addition, this study tries to investigate various ways to increase public transport ridership. The people awareness regarding benefits of public transport usage is also tested in this study. This study uses questionnaire and observation to collect data. The descriptive analysis based on the collected data shows that most of the people are aware of public transport benefits. These benefits include environment protection, reduction in parking demand and traffic congestion, lower travel cost (compare with private vehicle), fewer mental stresses, more safety, and being more convenient. Although people are aware of public transport benefits, there are some issues that prevent them to use public transport properly. Insufficient information about public transport schedules, lack of attractive facilities and suitable waiting stations and inadequate reliability are examples of issues that discourage people to use public transport. The results show that some improvements such as providing suitable information about public transport schedules, considering comfortable facilities to increase attractiveness, improving waiting facilities and reliability can encourage people to use public transport.
\end{abstract}

Keyword: Public transport; Medium sized cities; Developing countries; Suitable and attractive facilities; Public transport benefits; Public awareness

\section{INTRODUCTION}

Air pollution is a serious problem in developing and developed countries. Private motorized trips are considerable sources of air pollution. The rate of private motorized trips has been increased in developing countries. The total number of private cars has been increasing significantly between 1990 and 2008 (Ong, H.C. et al., 2012). Decrease private motorized trips and increase public transport usage can reduce air pollution 
Azin Bahreini, Hamed Mirzaei, Mehdi Moeinaddini, Zohreh Asadi-Shekari, Muhammad Zaly \& Zahid Sultan Evaluating Significant Factors that Influence Public Transport Usage in Kerman, Iran

(Grange et al., 2014; Rondinelli and Berry, 2000). In addition to the environmental benefits, increase public transport usage has also health benefits since public transport can increase walking and cycling (Grange et al., 2014).

Although using public transport can decrease environmental pollution and road traffic, public transport usage in developing countries is not considerable. For instance, Malaysia has the lowest public transport usage rate in Asia (Ong, H.C. et al., 2012). Furthermore, energy consumption in transportation sector has been increased significantly. Forty years ago, total energy consumption in this sector was between $15 \%$ and $20 \%$, but today is around 35\% and it is still increasing (Chapman, 2007). Public transport uses less fuel and energy than the private cars (Ong, H.C. et al., 2012). A good public transport system that can encourage people to shift from their own cars to public transport leads to decline private motorized trips, car ownership, energy consumption and traffic density (Wright, 2002).

There are various factors that influence public transport usage. These factors can be broken into socio-demographic factors (Brownson et al., 2000; Pucher and Renne 2003; Shaunna and Konstadinos, 2008; Burbidge et al., 2006; Ewing et al., 2003; Giles Corti and Donovan, 2002a; Pas and Koppelman 1986; and Coogan 2003), quality of service (STIMULUS, 1999; Hensher et al., 2003; Parasuraman et al., 1985; Balcombe et al., 2004; Xiong and Linbo, 2011; ZHOU et al., 2014; Zhang, F. 2011; Xu, G. 2008; and Kumar et al., 2004), reliability (Yatskiv et al., 2012; Balcombe et al., 2004; König, and Axhausen, 2002; Polus, 1978; and Vincent and Hamilton, 2008) and travel information provision (Eveleens M, 2011; Balcombe, et al., 2004; and Stradling, et al., 2001). Table 1 shows summary of factors that influence public transport usage.

There are various studies that show the effects of socio-demographic factors such as gender, age, education level and income on the public transport usage. Brownson et a (2000) found that women are more likely to use public transport more than men. Also women are more likely to walk for transport than men (Pucher and Renne 2003; Shaunna and Konstadinos, 2008). The youth (under age 19) and the elder people (more than 60) are more likely to use public transport (Burbidge et al., 2006; Ewing et al., 2003; and Pucher and Renne 2003) since the youth cannot obtain a driver's license and the elder people may lose their ability to drive with car and they prefer to use public transport (Shaunna and Konstadinos, 2008; Burbidge et al., 2006; Ewing et al 2003; and Pucher and Renne 2003).

Table 1: Summary of significant factors that influence public transport usage

\begin{tabular}{|l|c|c|c|c|l|}
\hline \multirow{2}{*}{ Model } & \multicolumn{3}{|c|}{ Factors } & \multirow{2}{*}{ Method } \\
\cline { 5 - 6 } & 1 & 2 & 3 & 4 & \\
\hline Brownson et al., 2000 & & & & & \\
\hline Pucher and Renne 2003 & $*$ & & & & Cross-sectional \\
\hline Shaunna and Konstadinos, 2008 & $*$ & & & & Questionnaire \\
\hline Burbidge et al., 2006 & $*$ & & & & Cross-sectional \\
\hline Ewing et al., 2003 & $*$ & & & & Questionnaire \\
\hline Giles Corti and Donovan, 2002a & $*$ & & & & Cross-sectional \\
\hline Pas and Koppelman 1986 & $*$ & & & & Questionnaire \\
\hline Coogan 2003 & $*$ & & & & Cross-sectional \\
\hline
\end{tabular}




\begin{tabular}{|l|c|c|c|c|l|}
\hline STIMULUS, 1999 & & $*$ & & & Correlation method \\
\hline Hensher et al., 2003 & & $*$ & & & Questionnaire \\
\hline Parasuraman et al., 1985 & & $*$ & & & Questionnaire \\
\hline Xiong and Linbo, 2011 & & $*$ & & & Questionnaire \\
\hline ZHOU et al., 2014 & & $*$ & & & Questionnaire \\
\hline Zhang, F. 2011 & & $*$ & & & Questionnaire \\
\hline Xu, G. 2008 & & $*$ & & & Questionnaire \\
\hline Kumar et al., 2004 & & $*$ & & & Questionnaire \\
\hline Yatskiv et al., 2012 & $*$ & $*$ & $*$ & $*$ & Questionnaire \\
\hline Balcombe et al., 2004 & & & $*$ & & Muestionnaire, Correlation method \\
\hline König, and Axhausen, 2002 & & & $*$ & & Questionnaire, Correlation method \\
\hline Polus, 1978 & & & $*$ & & Correlation method \\
\hline Vincent and Hamilton, 2008 & & & & $*$ & Questionnaire \\
\hline Eveleens M, 2011 & & & & $*$ & Qualitative method \\
\hline Stradling, et al., 2001 & & & & \\
\hline
\end{tabular}

1. Socio-demographic factors (gender, age, education level and income), 2. Quality of service (the waiting condition, attractiveness, travel time), 3. Reliability, 4. Travel information provision

In Perth, Australia people who have lower income use public transport more than the people with higher income (Giles Corti and Donovan, 2002a). Brownson et al 2001 and Pas and Koppelman, 1986 also found that the people with lower income use private cars less than the people with higher income even when they live in one neighborhood near each other. Educational level is also effective factor for public transport usage. For instance, Burbidge et al., (2006) and Coogan (2003) found that the people with higher educational level use public transport more than the people with lower educational level since educated people are more familiar with the advantages of public transport usage. In addition to the public transport usage educated people also walk more since they use public transport more.

It is needed to regulate the service quality which requested by people to have attractive public transport and encourage people to shift their travel modes to public transport (STIMULUS, 1999). To measure the quality of service, it is important to understand how people evaluate it (Hensher et al., 2003). From the service providers' vision, it is necessary to find the most significant attributes of service quality (Hensher et al., 2003). Some of these attributes such as safety and comfort cannot be measured easily (Parasuraman et al., 1985). Waiting condition is also important in service quality. Travelers prefer waiting for buses or trains in comfortable, clean and safe places while they have protection from bad weather condition (Balcombe et al., 2004, Xiong and Linbo).

Attractive service also can affect public transport usage. The attractiveness has different definitions in various studies. ZHOU et al., (2014) conducted a survey in Tongji Jiading campus in Shanghai to find the attractive factors for public transport usage. The results show that long distance, middle distance, and short distance are effective factors for attractiveness. Based on the findings, travel time is an important factor for people to choose public transport. Customers pay more attention to the attributes of the travel process such as safety and comfort in long distance travel. They also consider travel time, headway, fare and comfort for medium distance travel and travel time, headway, 
Azin Bahreini, Hamed Mirzaei, Mehdi Moeinaddini, Zohreh Asadi-Shekari, Muhammad Zaly \& Zahid Sultan Evaluating Significant Factors that Influence Public Transport Usage in Kerman, Iran

punctuality and distance to the station for short distance travel (ZHOU et al., 2014; Zhang, F. 2011; Xu, G. 2008; and Kumar et al., 2004).

Another factor that is important for both passenger and public transport operator is public transport reliability (Yatskiv et al., 2012). Reliability is providing a stable service during a period of time so, it depends on travel time reliability, waiting time reliability, arrival time reliability, and punctuality (Polus, 1978). Lack of reliability has effect on users in two ways: a delay when picking up the costumers and a delay when the costumers are on the service (Vincent and Hamilton, 2008). Reliability is one of the important characteristics for passengers in choosing mode of transport. If the public transport system is not reliable, most of the passengers choose private vehicles (Balcombe et al, 2004; König, and Axhausen, 2002).

People who want to use public transport need to have some basic level of information regarding public transport services (Eveleens M, 2011). Travel information provision is very important for public transport passengers and they use this information to plan their daily activities. Reliable and real travel information leads to increase possibility for passengers to reach their destinations on time (Eveleens M, 2011). Therefore, travel information provision can be one of the important factors for attractive public transport. The quality of public transport increases while travel information is sufficient (Eveleens, 2011). There are some studies that show information provision is one of the important factors that can encourage people to shift from private vehicles to public transport (e.g. Balcombe, et al., 2004; and Stradling, et al., 2001)

Although, public transport is one of the important green travel modes, the percentage of daily trips by public transport in Iran specially in medium sized cities such as Kerman is very low. In addition, the rate of vehicle usage in Iran is increasing in recent years (Verdinejad, 2010). There are lots of studies about significant factors that prevent public transport usage in developed countries but there are few studies in this area in developing countries. In some developing countries such as Iran, this issue is serious specially for medium sized cities like Kerman. Therefore, this study tries to identify effective factors that influence public transport usage in urban areas in developing countries like Iran. In addition, this study tries to investigate various ways to encourage public transport ridership. The people awareness regarding benefits of public transport usage is also tested in this study.

\section{MATERIAL AND METHODS}

In this survey the data are collected by questionnaire and observation. The target population includes people who are living in Kowsar neighborhood in Kerman (Iran). Kerman is located in the south east of Iran. Its population was 621,374 in 2011 and it is the 12th most populous city in Iran (Atapour and Aftabi, 2002). Figure 1 shows the general view of Kerman city and figure 2 shows general view of Kowsar neighborhood. The central parts of Kerman are historical neighborhoods. Nowadays, people are moving from these parts to the suburban areas such as Kowsar neighborhood since there are lots of barriers for development in historical neighborhoods. These barriers include lack of infrastructures, conservation regulations for historical neighborhoods, lack of facilities and etc. Kowsar is one of the suburban neighborhoods that attract lots of people in Kerman. Therefore, this study focuses on this neighborhood. 


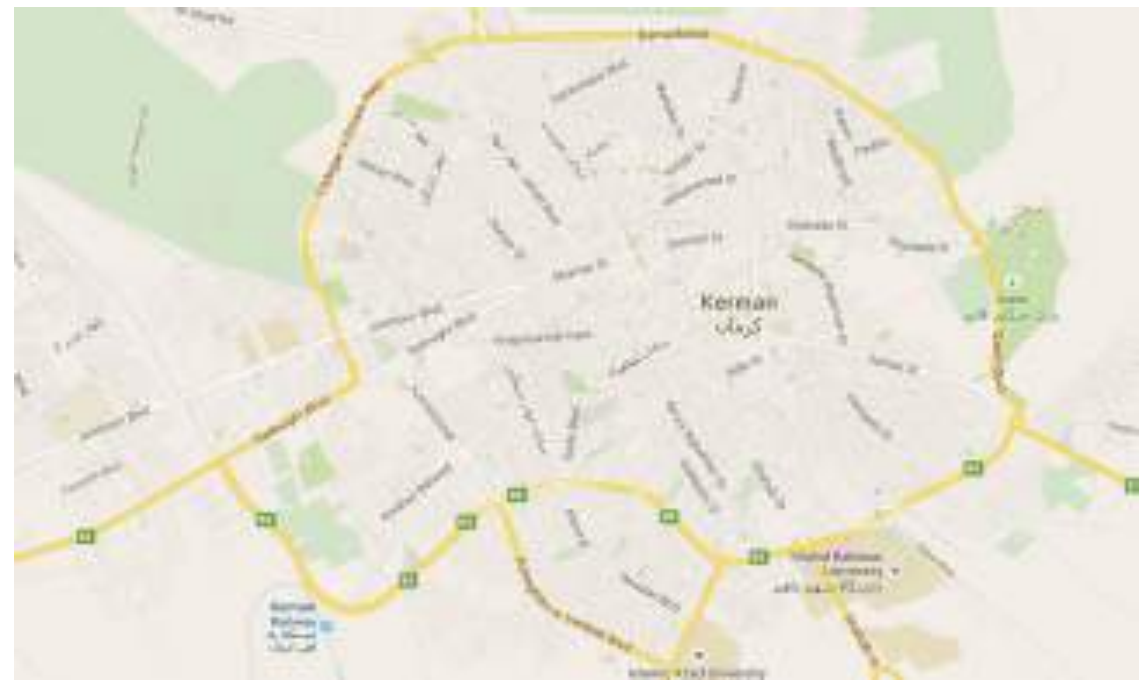

Figure 1: The general view of Kerman city

Source: Google map

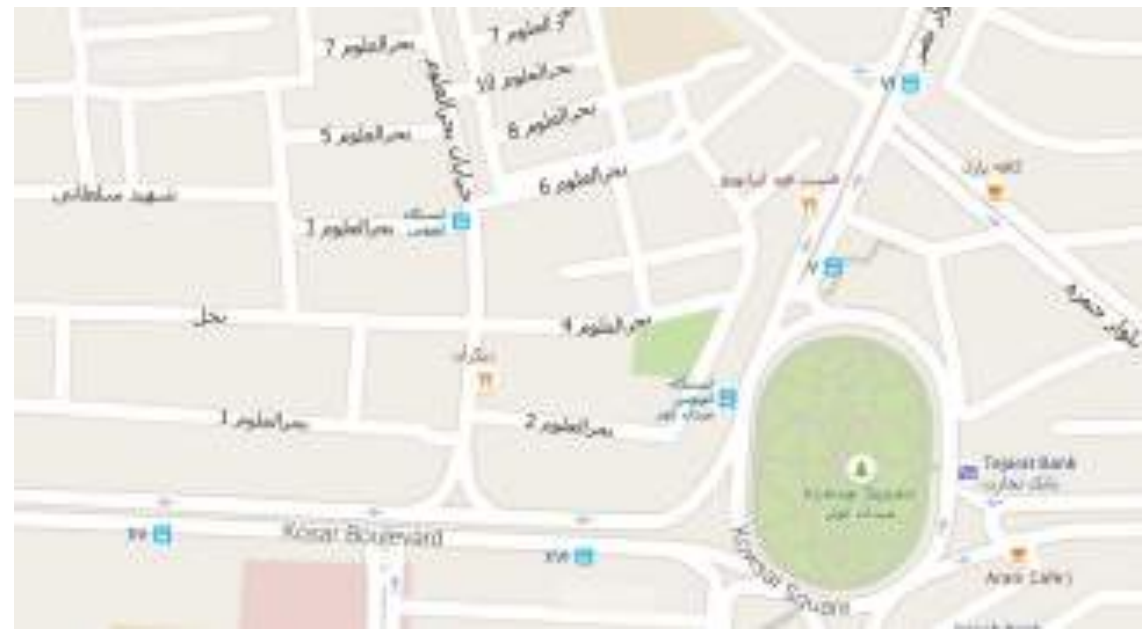

Figure 2: The general view of Kowsar neighborhood in Kerman Source: Google map

Descriptive data analysis was done by using Statistical Package for Social Studies (SPSS) (Patton, 1990). A survey questionnaire was prepared to record significant factors that influence public transport usage. Also survey questionnaire was adopted with site observation. The standardized questionnaire was used to collect data from a random sample including 100 respondents living in Kowsar neighborhood in Kerman city of Iran. This will be adequate sample size to have $95 \%$ confidence level and $10 \%$ margin of error base on Kowsar estimated population. 
Azin Bahreini, Hamed Mirzaei, Mehdi Moeinaddini, Zohreh Asadi-Shekari, Muhammad Zaly \& Zahid Sultan Evaluating Significant Factors that Influence Public Transport Usage in Kerman, Iran

The data collected through survey questionnaires can be divided into four parts. The first part is personal information that includes gender, age, education level, nature of job and income. The second part is about travel characteristics that include vehicle ownership and public transport frequency usage. The third part is about benefits of using public transport and factors that discourage public transport ridership. The last part is related to the accessibility, facilities and service quality. This part includes existing stations in the neighborhood, time to reach the stations, the safety of walking route from home to stations and convenience of the stations.

\section{RESULT}

The results show that only $14 \%$ of the respondents use public transport regularly. The results also indicate that $64 \%$ of the public transport users are female and $36 \%$ are male. Most of public transport users have diploma or bachelor degree (56\% of female and $40 \%$ of male who are using public transport have diploma and the rest have bachelor degree). The results also indicate that $13 \%$ of the public transport users use public transport for travelling to work, $39 \%$ use it for going shopping, $19 \%$ use it to reach educational centers and $29 \%$ use it for recreational purposes. Most of people who use public transport for travelling to work are male $(90 \%)$ while $75 \%$ of shopping purpose trips by public transport is related to female public transport riders. In addition, public transport is used by more females for travelling to the educational and recreational centers $(67 \%$ of travelers are female for both of educational and recreational purposes).

The results show that majority of people are familiar with public transport benefits Based on the results, 94\% of respondents believe that public transport can protect environment more than other motorized modes. They also believe that public transport usage can decrease parking problems and traffic congestions (92\% of the respondents). In addition, $85 \%$ of respondents think that using public transport is associated with lower costs compare with other motorized mode. Public transport is also effective to reduce stress and increase safety. This is mentioned by more than $60 \%$ of respondents.

The results also show that the people do not have serious problem with availability and accessibility of the stations (refer Table 2). Table 2 shows that majority of people are satisfied with the number of stations in the neighborhood. Table 2 also indicates that majority of people do not have safety problem while walking to the stations from home. This table also shows that the walking distance is not a serious issue. However, majority of the respondents are not convenient while they are waiting in the stations. 
Table 2: Respondent's satisfaction through availability and accessibility of the stations Enough stations in the neighborhood

\begin{tabular}{ll}
\hline Yes & \\
No & $19 \%$ \\
\hline Walking distance from home to stations & \\
\hline 5 to 10 minutes & $22 \%$ \\
\cline { 2 - 2 } 21 to 20 minutes & $59 \%$ \\
\cline { 2 - 2 } More than 30 minutes & $6 \%$ \\
\hline Safety of walking from home to stations & $13 \%$ \\
\hline Yes & \\
No & $87 \%$ \\
\hline Being convenient while waiting in the stations & $13 \%$ \\
\hline Yes & $21 \%$ \\
\cline { 2 - 2 } No & $79 \%$ \\
\hline
\end{tabular}

Although people are familiar with the benefits of using public transport and they do not have problem with the availability and accessibility of the stations, there are some issues that prevent people to use public transport. Based on the results, $93 \%$ of respondents believe that lack of information about public transport and schedules can prevent people to use public transport. They also believe that travel distance and travel time can affect public transport ( $80 \%$ of the respondents). In addition, more than $60 \%$ of respondents think that lack of attention to the role of some important factors such as being on time and reliability can reduce public transport usage. Attractiveness, amenities and the station condition are also effective factors for people to choose public transport. Lack of facilities and amenities can reduce public transport usage. This is mentioned by more than $70 \%$ of respondents.

\section{DISCUSSION AND CONCLUSION}

Although public transport is recommended by various studies to have a sustainable transport system, the results show that only $14 \%$ of the respondents use public transport regularly in Kerman (Iran). There are few studies about the significant factors that prevent people to use public transport in developing countries. There are only a few studies about public transport usage in Iranian megacities such as Tehran and medium sized cities such as Kerman have not been investigated. Therefore, this study tries to find effective factors that influence public transport usage in Kerman (Iran).

The results show that socio-demographic factors such as gender can influence public transport usage. Most of public transport users are female and they use public transport for travelling to the shopping, educational and recreational centers. However, public transport is used by more males for working trips. In addition, the people awareness regarding benefits of public transport usage is also tested in this study. The results show that majority of people are familiar with public transport benefits. These benefits include environment protection, reduction in parking demand and traffic congestion, lower travel cost (compare with private vehicle), fewer mental stresses, more safety, and being more convenient. The results also show that the people do not have serious problem with availability and accessibility of the stations. However, majority of the respondents are not convenient while they are waiting in the stations. 
Azin Bahreini, Hamed Mirzaei, Mehdi Moeinaddini, Zohreh Asadi-Shekari, Muhammad Zaly \& Zahid Sultan Evaluating Significant Factors that Influence Public Transport Usage in Kerman, Iran

Although people are aware of public transport benefits, there are some issues that prevent them to use public transport properly. Insufficient information about public transport schedules, lack of attractive facilities and suitable waiting stations and inadequate reliability are examples of issues that discourage people to use public transport. The results show that some improvements such as providing suitable information about public transport schedules, considering comfortable facilities to increase attractiveness, improving waiting facilities and reliability can encourage people to use public transport. Further studies are needed to find the limitations and solutions for implementing these improvements. In addition, future studies can improve the results by increasing sample size to reach lower margin of error.

\section{ACKNOWLEDGMENT}

The authors wish to thank all of those who have supported this research for their useful comments during its completion. In particular, we would like to acknowledge the Universiti Teknologi Malaysia Research Management Centre (RMC) and Centre for Innovative Planning and Development (CIPD). The funding for this project is made possible through the research grant obtained from the Ministry of Education, Malaysia under the Fundamental Research Grant Scheme (FRGS) 2014 (FRGS grant no:R.J130000.7821.4F602).

\section{REFERENCES}

Atapour, H., \& Aftabi, A. 2002. Geomorphological, geochemical and geo-environmental aspects of karstification in the urban areas of Kerman city, southeastern, Iran. Environmental Geology, 42(7), 783-792.

Balcombe, R., R. Mackett, N. Paulley, J. Preston, J. Shires, H. Titheridge, M. Wardman, P. White. 2004. The Demand for Public Transport: A Practical Guide. Transport Research Laboratory Report TRL No 593.

Brownson, R.C., R.A. Housemann, D.R. Brown, J. Jackson-Thompson, A.C. King, B.R. Malone, and J.F. Sallis. 2000. "Promoting Physical Activity in Rural Communities: Walking Trail Access, Use, and Effects." American Journal of Preventative Medicine. 18(3), 235-241.

Burbidge, S. K., K.G. Goulias, and T.G. Kim. 2006. "Travel Behavior Comparisons of Active Living and Inactive Living Lifestyles.” Proc., the 85th Annual Meeting of the Transportation Research Board, January 2006, Washington, D.C.

Chapman, L. 2007. Transport and climate change: a review. Journal of Transport Geography, 15(5), 354-367.

Clifton, K.J., Handy, S.L., 2001. Qualitative methods in travel behaviour research. Paper presented at the International Conference on Transport Survey Quality and Innovation, Kruger National Park, South Africa, August 2001.

Coogan, M.A. 2003. Why Care About Walking?: A celebration of the NHTS, accessed at http://nhts.ornl.gov/2001/presentations/walking/walking.ppt, August 2003.

Eveleens M, 2011, Travel Information Provision for the traveller in Public Transport. Can it be improved?

Ewing, R., T. Schmid, R. Killingsworth, A. Zlot, \& S. Raudenbush. 2003. "Relationship Between Urban Sprawl and Physical Activity, Obesity, and Morbidity.” American Journal of Health Promotion. 18(1), 47-57. 
Feng ZHOU1 , Jiajun HUANG2 and Ruihua XU, 2014. Study on Influencing Factors of Public Transport Attractiveness Based on the Binary Logit Model

Giles-Corti, B., and R.J. Donovan. 2002a. "Socioeconomic Status Differences in Recreational Physical Activity Levels and Real and Perceived Access to a Supportive Physical Environment." Preventive Medicine. 35, 601-611.

Grange, S. K., Dirks, K. N., Costello, S. B., \& Salmond, J. A. 2014. Cycleways and footpaths: What separation is needed for equivalent air pollution dose between travel modes ?, 32, 111-119.

H.C. Onga, T.M.I. Mahliaa, H.H. Masjukia 2012 A review on energy pattern and policy for transportation sector in Malaysia

Hensher, D. a., Stopher, P., \& Bullock, P. 2003. Service quality - developing a service quality index in the provision of commercial bus contracts. Transportation Research Part A: Policy and Practice, 37(6), 499-517. doi:10.1016/S09658564(02)00075-7

König, A. and Axhausen, Kay W. 2002. The reliability of the transportation system and its influence on the choice behaviour. Presentation at STRC 2002. In Proceedings of the 2nd Swiss Transport Research Conference, March 20

Kumar, P., Debashis B. and Maitra, B. 2004. "Modeling Generalized Cost of Travel for Rural Bus User: A Case Study.” Journal of Public Transportation, 7 (2): 59-72.

Parasuraman, A. Zeithaml, V., Berry L. 1985, “A Conceptual Model of Service Quality and its Implication for Future Research”, Journal of Marketing, Vol. 49, pp. 4150.

Pas, E.I., and F.S. Koppelman. 1986. "An Examination of the Determinants of Day to Day Variability in Individuals' Urban Travel Behavior.” Transportation. 13(2), 183-200.

Patton, M.Q., 1990. Qualitative evaluation and research methods. Sage Publications, Newbury Park, CA.

Polus, A. 1978. Modeling and Measurements of Bus Service Reliability. Transportation Research , 12(4), 253-256.

Pucher, J., and J.L. Renne. 2003. "Socioeconomics of Urban Travel: Evidence from the 2001 NHTS.” Transportation Quarterly. 57(3), 49-77.

Rondinelli and Berry, 2000. Multimodal Transportation, Logistics, and the Environment: Managing Interactions in a Global Economy

Shaunna K. Burbidge and Konstadinos G. 2008 , ACTIVE TRAVEL BEHAVIOR

STIMULUS 1999. Segmentation for transport in markets using latent user psychological structures. Transport Research Fourth Framework Programme, Office for Official Publications of the European Communities. Stradling, S.G., 2003. Reducing car dependence. In: Hine, J., Preston, J. (Eds.), Integrated Futures and Transport Choices. Ashgate Publications, Aldershot.

Stradling, S., Hine, J., \& Wardman, M. 2001 Physical, cognitive and effective effort in travel mode choices. Transport Research Laboratory.

Verdinejad, F. 2010. A review on Iran's Transportation History and its recent energy demand Issues. http://www.verdinejad.com/VisitorPages/show.aspx?IsDetailList=true\&ItemID= $15244,8 \&$ language $=$ en

Vincent and Hamilton 2008. Measurement Valuation of Public Transport Reliability 
Azin Bahreini, Hamed Mirzaei, Mehdi Moeinaddini, Zohreh Asadi-Shekari, Muhammad Zaly \& Zahid Sultan Evaluating Significant Factors that Influence Public Transport Usage in Kerman, Iran

Wright, L. 2002. Bus Rapid Transit, Institute for Transportation and Development Policy (IDPT)

Xiong, $\mathbf{J}$ and Linbo, L 2011. Influence of Bus Stop Waiting Environment on Competitiveness of Transit: What Factors Determine Traveler Choice? ICCTP 2011.

Xu, G. 2008. “An Empirical Study of Relationship among Service Quality, Passengers Satisfaction and Behavior Intention: An Example of BRT. System in Hangzhou." Zhejiang Gongshang University.

Zhang, F. 2011. "Ensuring traffic punctuality is key to enhancing the attractiveness of public transport." Assets and Finances in Administration and Institution, 4: 4-5. 